The 16th Economic International Conference

New Challenges and Opportunities for the Economy 4.0, May 7-8th, 2020, Suceava, Romania

\title{
Innovation Embraces Tradition - The Technology Impact on Interpretation of Cultural Heritage
}

\author{
Heike BÄHRE, Giovanni BUONO, Valerie Isabel ELSS \\ https://doi.org/10.18662/lumproc/ncoe4.0.2020/28
}

How to cite: Bähre, H., Buono, G., \& Elss, V.I. (2020). Innovation Embraces Tradition - The Technology Impact on Interpretation of Cultural Heritage. In C. Nastase (vol. ed.), Lumen Proceedings: Vol. 13. 16th Economic International Conference NCOE 4.02020 (pp. 319-326). Iasi, Romania: LUMEN Publishing House.

https://doi.org/10.18662/lumproc/ncoe4.0.2020/28 


\title{
Innovation Embraces Tradition - The Technology Impact on Interpretation of Cultural Heritage
}

\author{
Heike BÄHRE¹, Giovanni BUONO², Valerie Isabel ELSS ${ }^{3 *}$
}

\begin{abstract}
This article presents a current EU project on the methods of interpretation of European cultural beritage in the context of tourism. Around 453 cultural heritage sites are on the UNESCO World Heritage List within Europe [1]. Europe's cultural heritage is very diverse. This is by no means just about museums, castles or theatres; tradition and customs are also part of Europe's cultural heritage. As an essential part of the collective European memory, it is important to preserve this diversity. On the other side, the influence of new information and communication technologies (ICT) is increasing in all areas of society. How could the potentials of new developments within technology be instrumentalized within the interpretation of cultural heritage? To what extent does fintech (finance technology) tools like crowdfunding also play a decisive role in the interpretation of cultural heritage along with make it financially sustainable to align private and public interests? Based on a research project, the authors want to give empirical proposals of the usability of modern devices and technologies in the use of heritage interpretation and tourism marketing.
\end{abstract}

Keywords: Heritage and regional development; technology; methods of interpretation; crowdfunding; virtual reality.

\footnotetext{
${ }^{1}$ Fachhochschule des Mittelstands, Bielefeld, Germany, baehre@,fh-mittelstand.de

2 LUMSA University, Rome, Italy, giovanni@,fintechedulab.com

${ }^{3}$ Fachhochschule des Mittelstands, Bielefeld, Germany, elss@ffh-mittelstand.de

* Corresponding author. 


\section{Introduction}

The preservation of cultural heritage is a crucial task for the futurei.e. from an economic point of view. Within the EU, more than 300.000 people work in the field of cultural heritage, in addition around 7.8 million jobs in the EU are indirectly linked to cultural heritage (e.g. tourism) [3].

On one side, the initiative "Economy 4.0" raises awareness for digitalisation and networks as well as their consequences for business growth [6]. This also includes the tourism industry and more specific the heritage interpretation. Economy 4.0 will change the ways to respond to the needs and preferences of tourists - even in the sense of transferring knowledge about cultural heritage to tourists or within the experience design. On the other side, there are also implications for enhancing social cohesion. New trends will contribute to make cultural sights and even destinations accessible to all by removing social, cultural and physical barriers, to promote the development of a sustainable, responsible and high-quality tourism.

Some of the most innovative emerging technologies that has and will continue to have an ever-increasing use in various fields of heritage interpretation are Augmented Reality (AR), Virtual Reality (VR) and gamification techniques implemented through both traditional or digital devices and experiences for cultural heritage [2] [7].

Based on a research project, the authors want to demonstrate the usability of modern devices and technologies in the use of heritage interpretation and tourism marketing.

\section{EU-Project MIECAT (Methodology of Interpretation of European Cultural Heritage through Attractions in Tourism)}

Tilden (1957) defined heritage interpretation as "an educational activity which aims to reveal meanings and relationships through the use of original objects, by first-hand experience, and by illustrative media, rather than simply to communicate factual information" [13].The direct experience of cultural traditions is crucial in order to create a sustainable holiday experience for the tourist. Interpretation methods are very diverse (e.g. workshops, guided tours, tastings, but also virtual and augmented reality) and it may be difficult to generate an overview.

Taken this into account, six European universities are developing a study module (University of Applied Sciences (FHM), the Economic University Prague, the Economic University Bratislava, the Alexandru Ioan 
Cuza University, the University of Applied Sciences Burgenland and the Universidad Europea de Madrid) within a 3-year research project funded by Erasmus+ (MIECAT Methodology of Interpretation of European Cultural Heritage through Attractions in Tourism).

The developed module is intended to prepare students of tourism study programmes for the task of imparting knowledge about cultural heritage to tourists in order to support its continuance, but also to use cultural heritage in order to sustainably promote the development of tourism, including rural destinations. New technologies play a significant role within this process.

The sustainability of the project will be ensured through three central project outcomes:

- Syllabus (to implement the study module at six European universities)

- E-book (European cultural heritage, i.e. gastronomic traditions, the methods of its interpretation and transfer strategies for tourism markets).

- Guidelines for tourism companies focusing on the design and implementation of tourist attractions (best practice approaches, tourism needs analysis, market segmentation and event management).

\section{Argument of the paper}

Today, technology is part of almost every practical aspect of our life, not only as a tool to facilitate everyday tasks, but also as the main lens through which we approach and see reality. We learn and deepen our knowledge via computers and smartphone browsing the internet or directly via app. Even more, in these peculiar Covid-19 pandemic time, we have become accustomed to cooking, training, buying products, while interacting with friends and co-workers via digital devices. New business models, such as the delivery of food (and more in generally of any commodity) delivery skyrocketed. Existing trends that will accelerated in the following years. Obviously, the tourism industry will also be faced with these impacts and transformations, and the preservation of European cultural heritage, which is strictly linked to this, should take advantage of the opportunities that these changes will bring. What are possible approaches to take account of these changes in the framework of the interpretation of cultural heritage? 


\section{Influences of ICT on Tourism and Interpretation of Cultural Heritage}

The penetration of smartphones in the general population has reached $85 \%$ by 2018 , or, excluding the over- $55 \mathrm{~s}$, exceeds $95 \%$ [5]. The eTravel Report of Statista (2019) is forecasting that the global eTravel will grow to US $\$ 1,335.4$ billion by 2023 [12]. The share of "non-digital tourists" is only $11 \%$, while the rest carry out various activities such as searching for information, reviews, sharing experiences on social networks, etc.[12].

All these tendencies reflect a modern reality that ranges from the already aged Generation X and the Millennials to the growing audience of Generation Z. If these audiences are to be reached through the methods of interpretation of cultural heritage, innovative equipment, software and techniques must be integrated into a fully interactive experience. In this way, public and private institutions can also be supported in the "living" preservation of cultural heritage.

The following examples should underline this thesis:

- In the booming crowdfunding industry, which is mainly used to finance projects via apps and websites thanks to random and large numbers of Internet users, platforms are also used to preserve local elements of cultural heritage. An example is the reconstruction of a medieval castletransformed into a luxury condo hotel (now:Castellero Timeless Charm Resort, castle in the Piedmont region of Monferrato) [8] in a UNESCO protected area in northern Italy (project by Housers, a real estate crowdfunding company). Through this online platform, investors choose where, when, and how much to invest into real estate opportunities recommended by international experts [9]. Through this and other platforms, intersections for the preservation of cultural heritage can also be included.

In this case, the new technology and the new business model gave the location several advantages: economic support (therefore also sustainability), visibility to global audience on a scale impossible via traditional means, users of the platform become a kind of micro "Maecenas", developing a sense of belonging not thinkable with a simply visit to a cultural site.

- Using AR as an extension of the experience during a visit, such as trying a local and traditional food or participating in a 
traditional festival, makes the experience very similar to an "online" experience where all content is linked via hyperlinks, an application that allows you to "expand" your knowledge of what you are experiencing in terms of history or another cultural element. An example of an AR-application while interpreting cultural heritage can be seen in the CultApp project of the University of Applied Sciences (FHM). The project aims to inspire young people for Europe's culture. AR technologies are implemented into vocational education and training curricula for an enlarged culture experience [4].

- VR and more in general the phenomenon of simulated world, like the nowadays famous Fortnite, where during the lockdown period have been hosted a concert from pop singer attended by 12,8 million people. Using similar technology the museum of artwork and life of the architect Dali in Spain has created a faithful copy in a virtual world letting enjoy the place and organize virtual events during 2020 minimize the limitations occurred because of the Covid-19 pandemic[11].

\section{Limitations}

In order to also take account of possible limitations, we now list some points of criticism regarding the use of these innovations.

For example, it can be assumed that some aspects of cultural heritage (e.g. in the tasting of local traditional foods) do not appear to be transferable 1:1 through the use of digital technologies, because, for example, not all possible senses are taken into account. Those involved in the interpretation of cultural heritage may first need to acquire application skills; any reservations and fears of contact should be reduced. There is also the danger that technological devices act as a "distorting" filter for the authentic element.

Various research groups are addressing this issue. For example, Nikonova and Biryukova (2017) express a spontaneous concern from the most orthodox scientific community:

"Genuine knowledge and genuine artefacts of cultural heritage need not tobe used in actual practice, with the exception of a few scientific individuals' work. But most importantly, there will be no reason to preserve authentic remnants or ruins of historical and 
cultural monuments, as different digital technologies of 3D reconstruction, and digital simulations of life-size monuments will be perceived in society not only as an adequate substitute for the original, but as the only possibility to its perception. Therefore, virtual images of cultural heritage objects may prevail over their real images in our consciousness in the future." [10].

\section{Counterarguments in relation to the limitations} concerns:

Nevertheless, two relevant points are missing from the above

1. Technology and innovations have not to be taken as overall solution but mostly as a series of tools that can be selected and adapted to every single situation to strengthen the natural weaknesses of more traditional methods of maintaining and interpreting cultural heritage.

2. An "current" cultural heritage is in many cases the result of an interpretation of a previous element of cultural heritage influenced by technology of the past. The reader should reflect on how "old" technologies like press or radio had probably reinterpreted and had an impact on traditions when they appeared and became popular, presenting to us a "new" version of a particular tradition.

\section{Conclusions}

Cultural heritage conserves information of the past. It's shared in the form of long, factual-based interpretation methods that would only be appropriate for conferences, journals or passive live experiences. Meanwhile the world has gone digital and after the most recent events not only millennials and centennials (the first two native digital generations) but also boomers and their sons are becoming tech-savvy. Many cultural heritage institutions and the tourism industry linked to them needs to have on their agenda the priority to fill the gap between their traditional tools for preservation and promotion and an audience claiming a "phygital" approach combing all the new technological trends. Crowdfunding for financing and other fintechs for acquisition of product and services, VR and AR or the new social medias (such as twitch, tiktok, fortnite as "the languages" of younger generations) for promoting, interacting and sharing of information; 
Quick Response-Code (QR) and Near Field Communication (NFC) technology to access complementary contents on cultural sites or events. The tech jargon should not scare the outsider, all the above represent a challenge for the quality tourism industry and the cultural heritage preservation and at the same time an incredible opportunity for current professionals and new generation of operators to shorten cultural barriers or promote diversity and integration during an historical moment that is shaping the future of Europe.

\section{References}

[1] BMNT. Tourismus und Kultur - Kulturtourismus in Europa und Österreich europäisches Jahr des Kulturerbes Eych2018; 2018.

[2] Bontchev B. Serious Games for and as Cultural Heritage. Conference DIPP'2015; 2015.

[3] CHCfE Consortium. Cultural heritage counts for Europe. Full report. Krakow: International Culture Centre; 2015.

[4] CultApp partnership. Experiencing augmented reality on cultural heritage applications in vet; 2020 [cited 2020 May 24]. Available from: http://cultapp.eu/willkommen/.

[5] Deloitte. Global Mobile Consumer Survey, US Edition Overview of results; 2018 [cited 2020 May 24]. Available from: https://www2.deloitte.com/content/dam/Deloitte/us/Documents/technolo gy-media-telecommunications/us-tmt-global-mobile-consumer-surveyextended-deck-2018.pdf.

[6] European Commission. Economy 4.0; 2015 [cited 2020 May 6]. Available from: URL: https://ec.europa.eu/growth/tools-databases/regionalinnovation-monitor/policy-document/economy-40-0.

[7] Garcia-Fernandez J, Medeiros L. Cultural Heritage and Communication through Simulation Videogames-A Validation of Minecraft. Heritage. 2019; 2(3):2262-74.

[8] Housers. Housers. Sneak Peek: Palazzo Redoglia Project in Monferrato (Italy). Smart investment; 2018 [cited 2020 May 24]. Available from: URL: https://www.youtube.com/watch?v=a_xqDa8XUo4\&feature=youtu.be.

[9] Housers. Housers: Smart Investment; 2020 [cited 2020 May 24]. Available from: https://www.housers.com/en.

[10] Nikonova, AA \& Biryukova MV. The Role of Digital Technologies in the Preservation of Cultural Heritage. Muzeológia a kultúrnededičstvo 2017; 5(1):169-73.

[11] Salvador Dali Museum. Visit the museum as you have never done before!; 2020 [cited 2020 May 24]. Available from: URL: https://www.salvadordali.org/en/museums/dali-theatre-museum-in-figueres/visita-virtual/. 
Heike BÄHRE, ... | Lumen Proceedings 13 | NCOE4.0 2020

[12] Statista. eTravel Report 2019: Statista Digital Market Outlook - Market Report; 2019 [cited 2020 May 24]. Available from: https://de.statista.com/statistik/studie/id/42170/dokument/etravel-report/.

[13] Tilden F. Interpreting Our Heritage. Chapel Hill: The University of North Carolina Press; 1957. 